\title{
Evaluation of the efficacy of different sedative doses of dexmedetomidine on the intestinal motility in clinically healthy donkeys (Equus asinus)
}

\section{Marwa Abass ( $\nabla$ marwa_mossa@mans.edu.eg )}

Mansoura University, Anesthesiology and Radiology, Faculty of Veterinary Medicine, Mansoura University, Mansoura 35516, Mansoura, Egypt

\section{Hussam Ibrahim}

Internal Medicine, Infectious and Fish Diseases Faculty of Veterinary Medicine, Mansoura University, Mansoura 35516, Egypt

\section{Hakan Salci}

Department of Surgery, Faculty of Veterinary Medicine, Uludag Universitesi, Bursa, Turkey

\section{Mohamed Hamed}

Department of Surgery, Anesthesiology and Radiology, Faculty of Veterinary Medicine, Aswan University, Aswan 5677,Egypt

\section{Research Article}

Keywords: Dosage, Dexmedetomidine, Gastrointestinal tracts, Ultrasonography, Donkey

Posted Date: February 25th, 2022

DOI: https://doi.org/10.21203/rs.3.rs-1371198/v1

License: (c) (i) This work is licensed under a Creative Commons Attribution 4.0 International License. Read Full License 


\section{Abstract}

Background: The gastrointestinal effects of different doses of dexmedetomidine in donkeys are unknown. The study aimed to assess the impacts of different doses of dexmedetomidine on the motility of selected parts of the gastrointestinal tracts in donkeys using trans-abdominal ultrasonography. In-vivo experiment, a thirty healthful donkey of both sex (fifteen males and fifteen females; $160 \pm 60 \mathrm{~kg}$ ) received either normal saline solution or three different doses of dexmedetomidine $(3,5,7 \mu \mathrm{g} / \mathrm{kg})$ within two weeks washout period. All medications were given intravenously in equal volumes. The contractility of selected intestinal segments (duodenum, jejunum, left colon, right colon, and cecum) was totaled for three min before administration (zero time) and at 15, 30, 45, 60, 90, and 120 min after administration.

Results: There were no detectable clinical abnormalities on all selected donkeys, and they remained clinically healthy throughout the study period. Intravenous administration of dexmedetomidine markedly inhibited the small and large intestine motility when compared with saline treatment. The existing study revealed that Intravenous administration of dexmedetomidine reduces donkeys' small and large intestinal motility.

Conclusion: Intravenous administration of dexmedetomidine is a suitable sedative drug for donkeys when sedation and analgesia are needed for very short periods.

\section{Background}

Many surgical procedures are performed in horses using standing sedation and local blocks to avoid the risks of general anesthesia, making surgery easier due to posture height, and reducing blood loss, morbidity, mortality, and costs. Alpha-2 adrenergic receptor agonists are commonly utilized in equine to persuade sedation, analgesia, and muscle repose and facilitate diagnostic procedures and surgical interventions [1, 2].

Dexmedetomidine, the energetic medetomidine's enantiomer, is the key effective and exceedingly choosy alpha-2 adrenoceptor agonist with calming, analgesic, and muscle relaxant properties [3, 4]. Dexmedetomidine has beneficial pharmacological properties with a short half-life and rapid distribution, which encourages its use for infusion in horses, for example, allowing rapid changes in the depth of sedation and rapid recovery after the infusion has stopped [5].

Dexmedetomidine in donkeys, at a dose rate of $3-5 \mathrm{ug} / \mathrm{kg}$, stimulated sedation permanent to $60 \mathrm{~min}$ with a dose-based mechanical anti-nociception (40-55 $\mathrm{min}$ ). In contrast, dexmedetomidine at dose $5 \mathrm{ug} / \mathrm{kg}$ may be therapeutically effective for mild painful surgical procedures in standing sedation $[6,7]$.

Alpha-2 adrenoceptor agonists reduce the gastrointestinal motility in the horse [8-10], which is clinically important for horses suffering gastrointestinal motility disorders. Furthermore, general anesthesia in horses causes gastrointestinal hypo-motility [11], which may predispose to conditions such as ileus and caecal impaction $[12,13]$. On the other hand, dexmedetomidine inhibits rats' gastric emptying and gastrointestinal transit. In contrast, a study has assessed the effect of a low dose of dexmedetomidine in human gastrointestinal tracts, and it reveals inhibition of gastric emptying rate $[14,15]$. As the gastrointestinal effects of different iv. doses of dexmedetomidine in donkeys were unfamiliar; this research was designed to assess 
the impact of different doses of dexmedetomidine on the motility of nominated portions of the gastrointestinal tracts in donkeys using trans-abdominal ultrasonography.

\section{Results}

There were no detectable clinical abnormalities on all selected donkeys, and they remained clinically healthy during the research. No indications of regional IV infusion site reaction, sudden onset hypersensitivity, or nervous system disorders were recorded throughout the observing time following iv isotonic saline solution or dexmedetomidine at different doses used. IV injection of isotonic saline solution had no analgesia score 0 (00 ), sedation score $0(0-0)$, or ataxia score $0(0-0)$. IV injection of dexmedetomidine at a dose rate of 3,5 and 7 $\mu \mathrm{g} / \mathrm{kg}$ in the selected donkeys persuaded full mutual perineal analgesia with a noted score 3 (3-3) for each which was manifested by deficiency of sensation at the perineum, deficiency of anal sphincter reflex, tail flaccidity, and vulva relaxation in females. The analgesic influence of three different doses of dexmedetomidine started at 5th min post-administration and permanent to 90th min post-administration for 3 and $5 \mu \mathrm{g} / \mathrm{kg}$ and up to 120 th min post-administration for $7 \mu \mathrm{g} / \mathrm{kg}$ Table 1.

Table 1

Analgesia score post-intravenous injection of isotonic saline or Dexmedetomidine $(3,5$, and $7 \mu \mathrm{g} / \mathrm{kg})$ in Donkeys

\begin{tabular}{|c|c|c|c|c|c|c|c|c|}
\hline Group & $\begin{array}{l}\text { Time } \\
\text { zero }\end{array}$ & $\begin{array}{l}5 \\
\text { minutes }\end{array}$ & $\begin{array}{l}15 \\
\text { minutes }\end{array}$ & $\begin{array}{l}30 \\
\text { minutes }\end{array}$ & $\begin{array}{l}45 \\
\text { minutes }\end{array}$ & $\begin{array}{l}60 \\
\text { minutes }\end{array}$ & $\begin{array}{l}90 \\
\text { minutes }\end{array}$ & $\begin{array}{l}120 \\
\text { minutes }\end{array}$ \\
\hline $\begin{array}{l}\text { Normal saline ( } \mathrm{n} \\
=6 \text { ) }\end{array}$ & $\begin{array}{l}0 \\
(0- \\
0)^{a}\end{array}$ & $\begin{array}{l}0(0-0) \\
a\end{array}$ & $\begin{array}{l}0(0-0) \\
a\end{array}$ & $\begin{array}{l}0(0-0) \\
a\end{array}$ & $\begin{array}{l}0(0-0) \\
a\end{array}$ & $\begin{array}{l}0(0-0) \\
a\end{array}$ & $\begin{array}{l}0(0-0) \\
a\end{array}$ & $\begin{array}{l}0(0-0) \\
a\end{array}$ \\
\hline $\begin{array}{l}\text { Dexmedetomidine } \\
(3 \mu \mathrm{g} / \mathrm{kg})\end{array}$ & $\begin{array}{l}0 \\
(0- \\
0)^{a}\end{array}$ & $\begin{array}{l}3(2-3) \\
b\end{array}$ & $\begin{array}{l}3(2-3) \\
b\end{array}$ & $\begin{array}{l}3(3-3) \\
b\end{array}$ & $\frac{2}{b}(1-2)$ & $\begin{array}{l}1(1-1) \\
b\end{array}$ & $\begin{array}{l}1(0-1) \\
b\end{array}$ & $\begin{array}{l}0(0-0) \\
a\end{array}$ \\
\hline $\begin{array}{l}\text { Dexmedetomidine } \\
(5 \mu \mathrm{g} / \mathrm{kg})\end{array}$ & $\begin{array}{l}0 \\
(0- \\
0)^{a}\end{array}$ & $\begin{array}{l}3(3-3) \\
b\end{array}$ & $\begin{array}{l}3(3-3) \\
b\end{array}$ & $\begin{array}{l}3(3-3) \\
b\end{array}$ & $3(3-3)$ & $\begin{array}{l}2(1-2) \\
c\end{array}$ & $\begin{array}{l}2(1-2) \\
c\end{array}$ & $\begin{array}{l}0(0-0) \\
a\end{array}$ \\
\hline $\begin{array}{l}\text { Dexmedetomidine } \\
(7 \mu \mathrm{g} / \mathrm{kg})\end{array}$ & $\begin{array}{l}0 \\
(0- \\
0)^{a}\end{array}$ & $\begin{array}{l}3(3-3) \\
b\end{array}$ & $\begin{array}{l}3(3-3) \\
b\end{array}$ & $\begin{array}{l}3(3-3) \\
b\end{array}$ & $\begin{array}{l}3(3-3) \\
c\end{array}$ & $\begin{array}{l}3(3-3) \\
d\end{array}$ & $\begin{array}{l}2(2-3) \\
c\end{array}$ & $\begin{array}{l}0(0-1) \\
a\end{array}$ \\
\hline
\end{tabular}

IV injection of dexmedetomidine in donkeys at $3 \mu \mathrm{g} / \mathrm{kg}$ dose induced moderate sedation, manifested by intermittent retort to exterior stimuli, lethargy, and minor drop of the head, eyelids, and lips. The sedative effect of dexmedetomidine $(3 \mu \mathrm{g} / \mathrm{kg})$ started at the 5 th $\min$ and permanent to 45 th min post-administration. However, IV injection of dexmedetomidine in donkeys at 5 and $7 \mu \mathrm{g} / \mathrm{kg}$ doses induced deep sedation manifested by clear lethargy, dropped head, lips, and eyelids, and lack of response to external stimuli. The sedative effect of both doses of dexmedetomidine ( 5 and $7 \mu \mathrm{g} / \mathrm{kg}$ ) started at the 5 th min and lasted up to 90th min postadministration Table 2. 
Table 2

Sedation score post-intravenous injection of isotonic saline or Dexmedetomidine $(3,5$, and $7 \mu \mathrm{g} / \mathrm{kg})$ in Donkeys

\begin{tabular}{|c|c|c|c|c|c|c|c|c|}
\hline Group & $\begin{array}{l}\text { Time } \\
\text { zero }\end{array}$ & $\begin{array}{l}5 \\
\text { minutes }\end{array}$ & $\begin{array}{l}15 \\
\text { minutes }\end{array}$ & $\begin{array}{l}30 \\
\text { minutes }\end{array}$ & $\begin{array}{l}45 \\
\text { minutes }\end{array}$ & $\begin{array}{l}60 \\
\text { minutes }\end{array}$ & $\begin{array}{l}90 \\
\text { minutes }\end{array}$ & $\begin{array}{l}120 \\
\text { minutes }\end{array}$ \\
\hline $\begin{array}{l}\text { Normal saline ( } \mathrm{n} \\
=6 \text { ) }\end{array}$ & $\begin{array}{l}0 \\
(0- \\
0)^{a}\end{array}$ & $\begin{array}{l}0(0-0) \\
a\end{array}$ & $\begin{array}{l}0(0-0) \\
\mathrm{a}\end{array}$ & $\begin{array}{l}0(0-0) \\
a\end{array}$ & $\begin{array}{l}0(0-0) \\
a\end{array}$ & $\begin{array}{l}0(0-0) \\
a\end{array}$ & $\begin{array}{l}0(0-0) \\
\mathrm{a}\end{array}$ & $\begin{array}{l}0(0-0) \\
\mathrm{a}\end{array}$ \\
\hline $\begin{array}{l}\text { Dexmedetomidine } \\
(3 \mu \mathrm{kg} / \mathrm{kg})\end{array}$ & $\begin{array}{l}0 \\
(0- \\
0)^{a}\end{array}$ & $\begin{array}{l}2(1-2) \\
b\end{array}$ & $\begin{array}{l}2(2-2) \\
b\end{array}$ & $\begin{array}{l}2(2-3) \\
b\end{array}$ & $\begin{array}{l}1(1-1) \\
b\end{array}$ & $\begin{array}{l}1(0-1) \\
b\end{array}$ & $\begin{array}{l}0(0-1) \\
a\end{array}$ & $\begin{array}{l}0(0-1) \\
\mathrm{a}\end{array}$ \\
\hline $\begin{array}{l}\text { Dexmedetomidine } \\
(5 \mu \mathrm{kg} / \mathrm{kg})\end{array}$ & $\begin{array}{l}0 \\
(0- \\
0)^{a}\end{array}$ & $\begin{array}{l}3(2-3) \\
c\end{array}$ & $\begin{array}{l}3(3-3) \\
c\end{array}$ & $\begin{array}{l}3(3-3) \\
c\end{array}$ & $\begin{array}{l}2(2-2) \\
c\end{array}$ & $\begin{array}{l}2(1-2) \\
c\end{array}$ & $\begin{array}{l}1(1-2) \\
c\end{array}$ & $\begin{array}{l}0(0-1) \\
\mathrm{a}\end{array}$ \\
\hline $\begin{array}{l}\text { Dexmedetomidine } \\
(7 \mu \mathrm{gg} / \mathrm{kg})\end{array}$ & $\begin{array}{l}0 \\
(0- \\
0)^{a}\end{array}$ & $\begin{array}{l}3(3-3) \\
c\end{array}$ & $\begin{array}{l}3(3-3) \\
c\end{array}$ & $\begin{array}{l}3(3-3) \\
c\end{array}$ & $\begin{array}{l}3(2-3) \\
d\end{array}$ & $\begin{array}{l}2(1-2) \\
c\end{array}$ & $\begin{array}{l}1(1-2) \\
c\end{array}$ & $\begin{array}{l}0(0-1) \\
\mathrm{a}\end{array}$ \\
\hline
\end{tabular}

IV injection of dexmedetomidine in donkeys at 3,5 and $7 \mu \mathrm{g} / \mathrm{kg}$ doses induced moderate ataxia, which was manifested by marked stumbling walking but was very ataxic. Ataxia began at 5 th $\mathrm{min}$ after administration of all doses of dexmedetomidine and persisted up to 15 th min after administration for $3 \mu \mathrm{g} / \mathrm{kg}$, up to 30th min after administration for $5 \mu \mathrm{g} / \mathrm{kg}$ and up to 45th min after administration for $7 \mu \mathrm{g} / \mathrm{kg}$ Table 3 .

Table 3

Ataxia score post-intravenous injection of isotonic saline or Dexmedetomidine $(3,5$, and $7 \mu \mathrm{g} / \mathrm{kg})$ in Donkeys

\begin{tabular}{|c|c|c|c|c|c|c|c|c|}
\hline Group & $\begin{array}{l}\text { Time } \\
\text { zero }\end{array}$ & $\begin{array}{l}5 \\
\text { minutes }\end{array}$ & $\begin{array}{l}15 \\
\text { minutes }\end{array}$ & $\begin{array}{l}30 \\
\text { minutes }\end{array}$ & $\begin{array}{l}45 \\
\text { minutes }\end{array}$ & $\begin{array}{l}60 \\
\text { minutes }\end{array}$ & $\begin{array}{l}90 \\
\text { minutes }\end{array}$ & $\begin{array}{l}120 \\
\text { minutes }\end{array}$ \\
\hline $\begin{array}{l}\text { Normal saline ( } \mathrm{n} \\
=6 \text { ) }\end{array}$ & $\begin{array}{l}0 \\
(0- \\
0)^{a}\end{array}$ & $\begin{array}{l}0(0-0) \\
a\end{array}$ & $\begin{array}{l}0(0-0) \\
a\end{array}$ & $\begin{array}{l}0(0-0) \\
a\end{array}$ & $\begin{array}{l}0(0-0) \\
a\end{array}$ & $\begin{array}{l}0(0-0) \\
a\end{array}$ & $\begin{array}{l}0(0-0) \\
a\end{array}$ & $\begin{array}{l}0(0-0) \\
\mathrm{a}\end{array}$ \\
\hline $\begin{array}{l}\text { Dexmedetomidine } \\
(3 \mu \mathrm{kg} / \mathrm{kg})\end{array}$ & $\begin{array}{l}0 \\
(0- \\
0)^{a}\end{array}$ & $\begin{array}{l}2(2-2) \\
b\end{array}$ & $\begin{array}{l}2(2-2) \\
b\end{array}$ & $\begin{array}{l}1(1-1) \\
b\end{array}$ & $\begin{array}{l}1(1-1) \\
b\end{array}$ & $\begin{array}{l}0(0-0) \\
\mathrm{a}\end{array}$ & $\begin{array}{l}0(0-0) \\
\mathrm{a}\end{array}$ & $\begin{array}{l}0(0-0) \\
\mathrm{a}\end{array}$ \\
\hline $\begin{array}{l}\text { Dexmedetomidine } \\
(5 \mu \mathrm{gg} / \mathrm{kg})\end{array}$ & $\begin{array}{l}0 \\
(0- \\
0)^{a}\end{array}$ & $\begin{array}{l}2(2-2) \\
b\end{array}$ & $\begin{array}{l}2(2-2) \\
b\end{array}$ & $\begin{array}{l}2(2-2) \\
b\end{array}$ & $\begin{array}{l}1(1-1) \\
b\end{array}$ & $\begin{array}{l}1(1-1) \\
b\end{array}$ & $\begin{array}{l}0(0-0) \\
a\end{array}$ & $\begin{array}{l}0(0-0) \\
\mathrm{a}\end{array}$ \\
\hline $\begin{array}{l}\text { Dexmedetomidine } \\
(7 \mu \mathrm{gg} / \mathrm{kg})\end{array}$ & $\begin{array}{l}0 \\
(0- \\
0)^{a}\end{array}$ & $\begin{array}{l}2(2-2) \\
b\end{array}$ & $\begin{array}{l}2(2-2) \\
b\end{array}$ & $\begin{array}{l}2(2-2) \\
b\end{array}$ & $\begin{array}{l}1(1-2) \\
b\end{array}$ & $\begin{array}{l}1(1-1) \\
b\end{array}$ & $\begin{array}{l}0(0-0) \\
a\end{array}$ & $\begin{array}{l}0(0-0) \\
\mathrm{a}\end{array}$ \\
\hline
\end{tabular}


In the donkeys, small and large intestines' motility was within normal ranges before IV injection of normal isotonic saline or dexmedetomidine at 3,5 , and $7 \mu \mathrm{g} / \mathrm{kg}$ doses.

Two Way Repeated Measures Anova's output of the data displayed a statistically significant $(p<0.05)$ binding between time and both treatment for the contractility of each of the duodenum, jejunum, left colon, right colon, and cecum, implying that the impact of treatment varied among different time points.

Simple main effect analysis showed that IV dexmedetomidine at 3, 5 and $7 \mu \mathrm{g} / \mathrm{kg}$ doses significantly altered bowel contractility compared to administration of isotonic saline $(P<0.05)$.

After IV injection of common saline in the donkeys under experiments, the contractility of each of the examined portions of the small and large intestine did not significantly fluctuate during the two hours driving period and stayed within the typical levels till 120th min post-administration. Nevertheless, after IV injection of dexmedetomidine in the chosen donkeys, the contractility of each of the examined portions of the small and large intestine were qualitatively and quantitatively changed (Figs. 1-5).

Intravenous dexmedetomidine at $3 \mu \mathrm{g} / \mathrm{kg}$ dose caused a significant decline in both the duodenal and jejunal motility form equated with placebo at $15,30,45$, and 60 th min post-injection. The smallest contractions (contractions / $3 \mathrm{~min}$ ) of both duodenum and jejunum were $3.5 \pm 1.2$ and $3.5 \pm 1.3$, respectively, which were noted at 30 min post-administration. However, dexmedetomidine at 5 and $7 \mu \mathrm{g} / \mathrm{kg}$ doses caused a significant reduction in both duodenal and jejunal motility patterns equaled to placebo at $15,30,45,60$, and 90 th min post-injection. The smallest contractions (contractions / $3 \mathrm{~min}$ ) of both duodenum and jejunum after IV dexmedetomidine $(5 \mu \mathrm{g} / \mathrm{kg}$ ) were $2.7 \pm 1.0$ and $2.5 \pm 1.0$, separately, which were noted at 45th min postadministration. The lowest contractions (contractions / $3 \mathrm{~min}$ ) of both duodenum and jejunum after IV dexmedetomidine at $7 \mu \mathrm{g} / \mathrm{kg}$ were $1.5 \pm 1.1$ and $1.5 \pm 1.1$, respectively, which were noted at 60 th min postadministration (Figs. 1,2).

Motility of left colon decreased significantly at 15-, 30-, and 45-min post IV injection of $3 \mu \mathrm{g} / \mathrm{kg}$ of dexmedetomidine compared to placebo. While both the duodenal and jejunal motility showed a significantly decreased at 15-, 30-, and 45-min post IV injection of 5 and $7 \mu \mathrm{g} / \mathrm{kg}$ of dexmedetomidine compared to placebo. The smallest contractions (contractions / $3 \mathrm{~min}$ ) of the left colon motility after IV dexmedetomidine at $3 \mu \mathrm{g} / \mathrm{kg}$ were $2.3 \pm 1.3,5 \mu \mathrm{g} / \mathrm{kg}$ were $1.5 \pm 1.2$, and $7 \mu \mathrm{g} / \mathrm{kg}$ were $1.1 \pm 1.0$, that were recorded at $30-, 45-$, and 60 -min post-injection (Fig. 3).

IV dexmedetomidine at 3,5 and $7 \mu \mathrm{g} / \mathrm{kg}$ caused a significant decline in the right colon motility equated to placebo at 15, 30-, 45-, 60-, and 90-min post-injection. The smallest contractions (contractions / $3 \mathrm{~min}$ ) of the right colon motility after IV dexmedetomidine at $3 \mu \mathrm{g} / \mathrm{kg}$ were $4.0 \pm 1.1,5 \mu \mathrm{g} / \mathrm{kg}$ were $2.9 \pm 1.1$, and $7 \mu \mathrm{g} / \mathrm{kg}$ were $1.5 \pm 1.0$, which were recorded at 30-, 45-, and 60-min post-administration (Fig. 4).

Similarly, dexmedetomidine of $3 \mu \mathrm{g} / \mathrm{kg}$ caused a significant decline in the cecum motility pattern compared to placebo at 15-, 30-, 45-, and 60-min post-injection. However, dexmedetomidine of 5 and $7 \mu \mathrm{g} / \mathrm{kg}$ caused a significant decline in the cecum motility form associated to placebo at 15, 30-, 45-, 60-, and 90-min postinjection. The smallest contractions (contractions / $3 \mathrm{~min}$ ) of the cecum motility after intravenous 
dexmedetomidine at a dose ratio of $3 \mu \mathrm{g} / \mathrm{kg}$ were $1.7 \pm 1.1,5 \mu \mathrm{g} / \mathrm{kg}$ were $1.2 \pm 1.1$, and $7 \mu \mathrm{g} / \mathrm{kg}$ were 1.0 \pm 1.0 , which were recorded at 30-, 45-, and 60-min post-administration (Fig. 5).

\section{Discussion}

In this current study, the analgesic effect of dexmedetomidine was observed 5th min after IV administration and lasted at 30th min post-administration for $3 \mu \mathrm{g} / \mathrm{kg}$ dose, $45 \mathrm{~min}$ for $5 \mu \mathrm{g} / \mathrm{kg}$, and $60 \mathrm{~min}$ for $7 \mu \mathrm{g} / \mathrm{kg} \mathrm{dose}$ that also recorded by $[6,7]$.. However, the sedative effect of dexmedetomidine was observed 5 min after its IV administration and lasted 60 min post-administration for $3 \mu \mathrm{g} / \mathrm{kg}$ dose, and $90 \mathrm{~min}$ for both 5 and $7 \mu \mathrm{g} / \mathrm{kg}$. Therefore, dexmedetomidine has a beneficial pharmacological profile with rapid redistribution and a short halflife $[16,17]$. There were significant differences between treatments for the analgesia and sedation scores. However, insignificant differences were observed among treatments for the ataxia scores.

The anatomical location and the ultrasonographic presence of the visualized sections of both the small and large intestine using abdominal ultrasonography agreed with those previously described [18, 19]. Before IV injection of normal isotonic saline or different selected doses of dexmedetomidine in the donkeys under trials, the regularity of contractility of both small (duodenum and jejunum) and large (left colon, right colon, and cecum) intestines were inside the ordinary varies, which are directly comparable those informed by $[18,20$, 21].IV injection of isotonic saline solution in the donkeys did not influence the contractility of the visualized sections of the small and large intestine during 120th min motoring period and stayed inside the ordinary varies till 120th min post-injection as formerly described in humans [22].

The effect of different doses of dexmedetomidine on gastrointestinal motility was consistent across all donkeys within 90th min $\mathrm{a}_{2}$-adrenoceptor agonists, including clonidine and dexmedetomidine, induce sedation, decline anesthetic and analgesic circumstances, and enhance peri-operative hemodynamic steadiness [23]. In contrast, they mitigate gastric, small bowel, and colonic motility in animal and human studies [24].

In donkey, the effect of IV dexmedetomidine began at 5th min and lasted up to 30-90 min based on the dose given. The results of pharmacokinetics studies revealed that dexmedetomidine concentrations decreased rapidly with elimination half-life ranging between 7.19 and $8.87 \mathrm{~min}$, and the last detection time varied between 30 and $60 \mathrm{~min}$. The plasma concentrations of dexmedetomidine peaked 1-4 min post-administration [25].

In the limitations of this study, exploration of the pharmacokinetics of dexmedetomidine in donkeys is lacking, which may not concede a whole elucidation of the given findings. As the current study was performed on healthy donkeys depending on the investigational design, the given findings may not expose the true specification of diseased donkeys with disturbed gastrointestinal tract motor function. Thus, additional investigations are demanded to estimate the influence of this drug in donkeys with disturbed gastrointestinal tract motor function.

\section{Conclusion}

The existing study revealed that IV administration of dexmedetomidine is a suitable sedative drug for donkeys when sedation and analgesia are needed for very short periods. Dexmedetomidine reduces the small and large intestinal motility in such animal species, indicating the possible adverse effect of such drug on the 
gastrointestinal tract motor function. Consequently, it might be useful to draw awareness to this potential unfavorable effect, especially when used in equines with disturbed gastrointestinal tract motility patterns.

\section{Methods}

\section{Study sample}

A 30 healthy donkey (Equus asinus) (15males and 15 females) aged between 5 and 9 years old and weighed between 100 and $220 \mathrm{~kg}$ were included in the study. The donkeys were located in the stalls interior the animal barn for two weeks before the study. The donkeys were inoculated and dewormed, on arrival, via the ivermectin glue (Bimectin ${ }^{\circledR}$, Bimeda Animal Health Ltd., Ireland) at a dosage rate of $0.2 \mathrm{mg} / \mathrm{kg}$. The feeding regimen for the selected donkeys was a uniformly balanced share comprising sliced wheat straw ad libitum, grain (1.5 kg), and crushed corn $(1.5 \mathrm{~kg})$, supplemented with all the necessary trace elements and minerals, which was offered twofold a day at fixed times; 7.00 am and $7.00 \mathrm{pm}$, intending to decline the impact of the kind of the intake on the motility of the gastrointestinal tract. Furthermore, tap water was constantly supplied during the day. The Animal Welfare and Ethics Committee of the Faculty of Veterinary Medicine, Code No. R/63 validated all animal care and testing procedures following the Guidelines for Animal Use and Care published by the Faculty of Veterinary Medicine, Mansoura University, Egypt

\section{Study design}

Each donkey was placed in four trials, with a two-week gap between the next, which normally began one hour after feeding. The first one (placebo) was carried out by IV $20 \mathrm{ml}$ normal isotonic saline. The second, third and fourth groups were directed by dexmedetomidine (Precedex ${ }^{\circledR}$, Lakeforest, USA) at the dosage of 3,5 and $7 \mu \mathrm{g} /$ $\mathrm{kg}$ iv. respectively. After preparing the required dose of dexmedetomidine for each donkey, the medication was modified to be a $20 \mathrm{~mL}$ end volume by combining normal saline. One-third of the dose was administered as IV bolus where the remaining two-thirds were injected slowly over $2 \mathrm{~min}$

In the experiment donkeys, the level of analgesia, sedation, and ataxia was measured using the 0 to 3 scoring system as previously described [26]. The degree of anti-nociception, analgesia, sedation, and ataxia were measured before injection (time zero) and at 15, 30, 45, 60, 90, and 120 min after injection. Each trial initiated 1 $\mathrm{h}$ after consuming in this study as the solid phase of gastric discharging begins within $30 \mathrm{~min}$ of eating. The motility of each of the duodenum, jejunum, left colon, right colon, and cecum was counted over 3 min via transabdominal ultrasonography before administration (time zero) and at 15, 30, 45, 60, 90, and 120 min after injection of the medicament. There was no inlet to food or water throughout the observing periods, there was no access to food or water.

\section{Transabdominal Ultrasonography}

The abdominal region expanding from the 7th intercostal space backward up to the lumbar fossa was bilaterally clipped and prepared for the ultrasonographical examination. The coupling gel was applied to those areas, and a linear transducer (2.5-5 MHz) (iVis 60 Expert Vet ${ }^{\circledR}$, Chison Medical Imaging Co. Ltd., China) was selected. The scan depth was initially set to the maximum penetration and then was adjusted to different depths according to the individual structure being scanned to obtain the best definition of structures and to maximize image quality. The left colon and jejunum were scanned from the left abdominal wall, and 
duodenum, right colon, and cecum were examined from the right abdomen. The physiological position and structure on the ultrasound image were used to identify the specific parts of the intestine in each donkey, as previously noted $[18,19]$. All ultrasound procedures to qualitatively and quantitatively assess the motility of the selected parts of the intestine were initiated $1 \mathrm{~h}$ after feeding (at 8:00 am) and were done by the identical person to prevent any particular fluctuations and reviewed by two experienced subjects.

\section{Data analysis}

It was achieved via SPSS software for Windows, version 21.0; IBM Inc, Chicago, IL). The assessed data were normally distributed based on the Kolmogorov-Smirnov test output. At different time points, the nonparametric Kruskal-Wallis test with post hoc Dunn's multiple comparison test was utilized to evaluate statistical differences between scored parameters (analgesia, sedation, and ataxia) treatments. For parametric data of the intestinal contractility pattern, Two Way Repeated Measures ANOVA was used to evaluate the impact of time, treatment, and interaction between time and treatment. Wilks' lambda test was chosen to evaluate within-group and time $x$ treatment binding evidence. Meanwhile, Wilks' lambda test revealed a statistically significant difference among groups, the One-Way ANOVA test was utilized at each time point to distinguish which group was statistically different. The data have been presented in run charts of the intestinal cramps vs. each time point during the observation period in both experiments. The findings are significant at $p$ $<0.05$ in all statistical analyses.

\section{Declarations}

\section{Acknowledgements}

The authors would like to thank the staff at department of Veterinary Surgery, Anesthesiology and RadiologyMansoura university for their assistance.

\section{Authors' contributions}

Abbas $\mathrm{M}$ and Hamed MA performed the experiments and drafted the paper. Ibrahim HMM analyzed the data and contributed to the final revision and submission.

\section{Funding}

No funding was received for this study.

\section{Availability of data and materials}

All data generated or analysed during this study are included in this article.

\section{Declarations}




\section{Ethics approval and consent to participate}

This study was approved by the Welfare and Ethics Committee of the Faculty of Veterinary Medicine, Mansoura University, Egypt (Code No. R/63). All procedures in this study were performed in accordance with the tenets of the Basel Declaration, guidelines of the International Council for Laboratory Animal Science (ICLAS), and the American Veterinary Medical Association (AVMA) Guidelines for the Euthanasia of Animals (2020). The study was carried out in compliance with the ARRIVE guidelines. Moreover, informed consent to use the donkeys in this study were obtained from their owner.

\section{Consent for publication}

Not applicable.

\section{Competing interests}

The authors declare that they have no competing interests.

\section{Author details}

${ }^{1}$ Department of Surgery, Anesthesiology and Radiology, Faculty of Veterinary Medicine, Mansoura University, Mansoura 35516, Egypt. ${ }^{2}$ Department of Internal Medicine and Infectious Diseases, Faculty of Veterinary Medicine, Aswan University, Egypt. ${ }^{3}$ Department of Surgery, Faculty of Veterinary Medicine, Uludag Universitesi, Bursa, Turkey. ${ }^{4}$ Department of Surgery, Anesthesiology and Radiology, Faculty of Veterinary Medicine, Aswan University, Egypt.

\section{References}

1. Daunt DA, Steffey EP. Alpha-2 adrenergic agonists as analgesics in horses. Vet Clin Equine Pract. 2002;18:39-46.

2. Valverde A. Alpha-2 agonists as pain therapy in horses. Vet Clin Equine Pract. 2010;26:515-32.

3. Posner LP, Burns P. Sedative agents: tranquilizers, alpha-2 agonists, and related agents. Vet Pharmacol Ther JE Riviere MG Papich, Ed. 2009;:337-80.

4. Risberg Ål, Ranheim B, Krontveit RI, Lervik A, Haga HA. The cardiovascular status of isofluraneanaesthetized horses with and without dexmedetomidine constant rate infusion evaluated at equivalent depths of anaesthesia. Vet Anaesth Analg. 2016;43:412-23.

5. Medeiros LQ, Gozalo-Marcilla M, Taylor PM, Campagnol D, De Oliveira FA, Watanabe MJ, et al. Sedative and cardiopulmonary effects of dexmedetomidine infusions randomly receiving, or not, butorphanol in standing horses. Vet Rec. 2017;181:402.

6. Lizarraga I, Castillo-Alcala F, Robinson LS. Comparison of sedation and mechanical antinociception induced by intravenous administration of acepromazine and four dose rates of dexmedetomidine in 
donkeys. Vet Anaesth Analg. 2017;44:509-17.

7. Lizarraga I, Janovyak E. Comparison of the mechanical hypoalgesic effects of five a2-adrenoceptor agonists in donkeys. Vet Rec. 2013;173:294.

8. Adams SB, Lamar CH, Masty J. Motility of the distal portion of the jejunum and pelvic flexure in ponies: effects of six drugs. Am J Vet Res. 1984;45:795-9.

9. Lester GD, Merritt AM, Neuwirth L, Vetro-Widenhouse T, Steible C, Rice B. Effect of alpha 2-adrenergic, cholinergic, and nonsteroidal anti-inflammatory drugs on myoelectric activity of ileum, cecum, and right ventral colon and on cecal emptying of radiolabeled markers in clinically normal ponies. Am J Vet Res. 1998;59:320-7.

10. Merritt AM, Burrow JA, Hartless CS. Effect of xylazine, detomidine, and a combination of xylazine and butorphanol on equine duodenal motility. Am J Vet Res. 1998;59:619-23.

11. Lester GD, Bolton JR, Cullen LK, Thurgate SM. Effects of general anesthesia on myoelectric activity of the intestine in horses. Am J Vet Res. 1992;53:1553-7.

12. Campbell ML, Colahan PC, Brown MP, Grandstedt ME, Peyton LC. Cecal impaction in the horse. J Am Vet Med Assoc. 1984;184:950-2.

13. HUNT JM, Edwards GB, CLARKE KW. Incidence, diagnosis and treatment of postoperative complications in colic cases. Equine Vet J. 1986;18:264-70.

14. Asai T, Mapleson WW, Power I. Differential effects of clonidine and dexmedetomidine on gastric emptying and gastrointestinal transit in the rat. Br J Anaesth. 1997;78:301-7.

15. lirola T, Vilo S, Aantaa R, Wendelin-Saarenhovi M, Neuvonen PJ, Scheinin M, et al. Dexmedetomidine inhibits gastric emptying and oro-caecal transit in healthy volunteers. Br J Anaesth. 2011;106:522-7.

16. Bettschart-Wolfensberger R, Freeman SL, Bowen IM, Aliabadi FS, Weller R, Huhtinen M, et al. Cardiopulmonary effects and pharmacokinetics of iv dexmedetomidine in ponies. Equine Vet $\mathrm{J}$. 2005;37:60-4.

17. Gozalo-Marcilla M, Gasthuys F, Luna SPL, Schauvliege S. Is there a place for dexmedetomidine in equine anaesthesia and analgesia? A systematic review (2005-2017). J Vet Pharmacol Ther. 2018;41:205-17.

18. Ibrahim HMM, El-Ashker MR. Reference values and repeatability of transabdominal ultrasonographic gastrointestinal tract thickness and motility in healthy donkeys (equus asinus). J Equine Vet Sci. 2020;92:103153.

19. Farag AMM, Ibrahim HMM. Does Intravenous Ondansetron Affect the Intestinal Motility Pattern in Healthy Donkeys (Equus asinus)? J Equine Vet Sci. 2021;101:103427.

20. Gomaa NA, Ibrahim HMM, Ishii M, Nassif MN, El-khodery SA. Dose-dependent effects of mosapride citrate on duodenal and cecal motility in donkeys (Equus asinus). Int J Vet Sci Med. 2013;1:51-6.

21. Ibrahim HMM, Gomaa NA, El-Mahmoudy A, El-khodery SA, Ishii M, Nassif MN. Ultrasonographic evaluation of duodenal and cecal motility after administration of different doses of domperidone in donkeys. Equus Asinus. 2013;:179-87.

22. Stevens JE, Doran S, Russo A, O’Donovan D, Feinle-Bisset C, Rayner CK, et al. Effects of intravenous fructose on gastric emptying and antropyloroduodenal motility in healthy subjects. Am J Physiol Liver Physiol. 2009;297:G1274-80. 
23. Chang H, Li S, Li Y, Hu H, Cheng B, Miao J, et al. Effect of sedation with dexmedetomidine or propofol on gastrointestinal motility in lipopolysaccharide-induced endotoxemic mice. BMC Anesthesiol. 2020;20:111.

24. Fruhwald $\mathrm{S}$, Holzer $\mathrm{P}$, Metzler $\mathrm{H}$. Intestinal motility disturbances in intensive care patients pathogenesis and clinical impact. Intensive Care Med. 2007;33:36-44.

25. Rezende ML, Grimsrud KN, Stanley SD, Steffey EP, Mama KR. Pharmacokinetics and pharmacodynamics of intravenous dexmedetomidine in the horse. J Vet Pharmacol Ther. 2015;38:15-23.

26. Hamed MA, Abouelnasr KS, Ibrahim HMM, El-Khodery SA. Comparative, sedative, and analgesic effects of epidural dexmedetomidine and xylazine in donkeys (Equus asinus). J Equine Vet Sci. 2017;59:104-9.

\section{Figures}

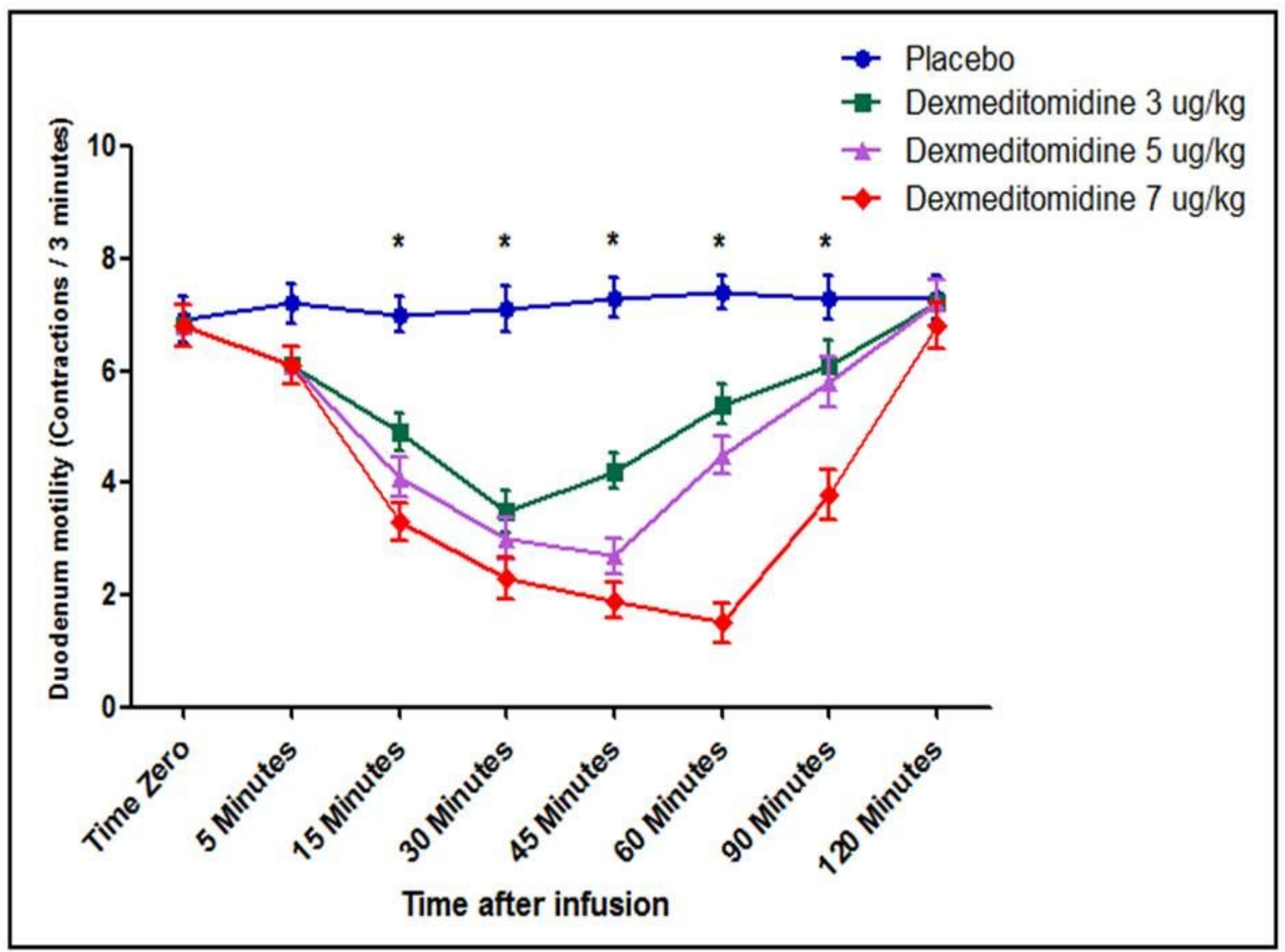

\section{Figure 1}

The duodenum motility pattern in healthy donkeys (Equus asinus) after IV administration of isotonic saline or dexmedetomidine at 3,5 and $7 \mu \mathrm{g} / \mathrm{kg}$. Each point represents the number of contractions (contractions / 3 
minutes) expressed as mean \pm standard deviation (SD) at different time points zero, 5, 15, 30, 45-, 60-, 90-, and 120-minutes post-administration. *: Mean \pm SD with a superscript asterisk at the same time point are significantly different at $\mathrm{p}<0.05$.

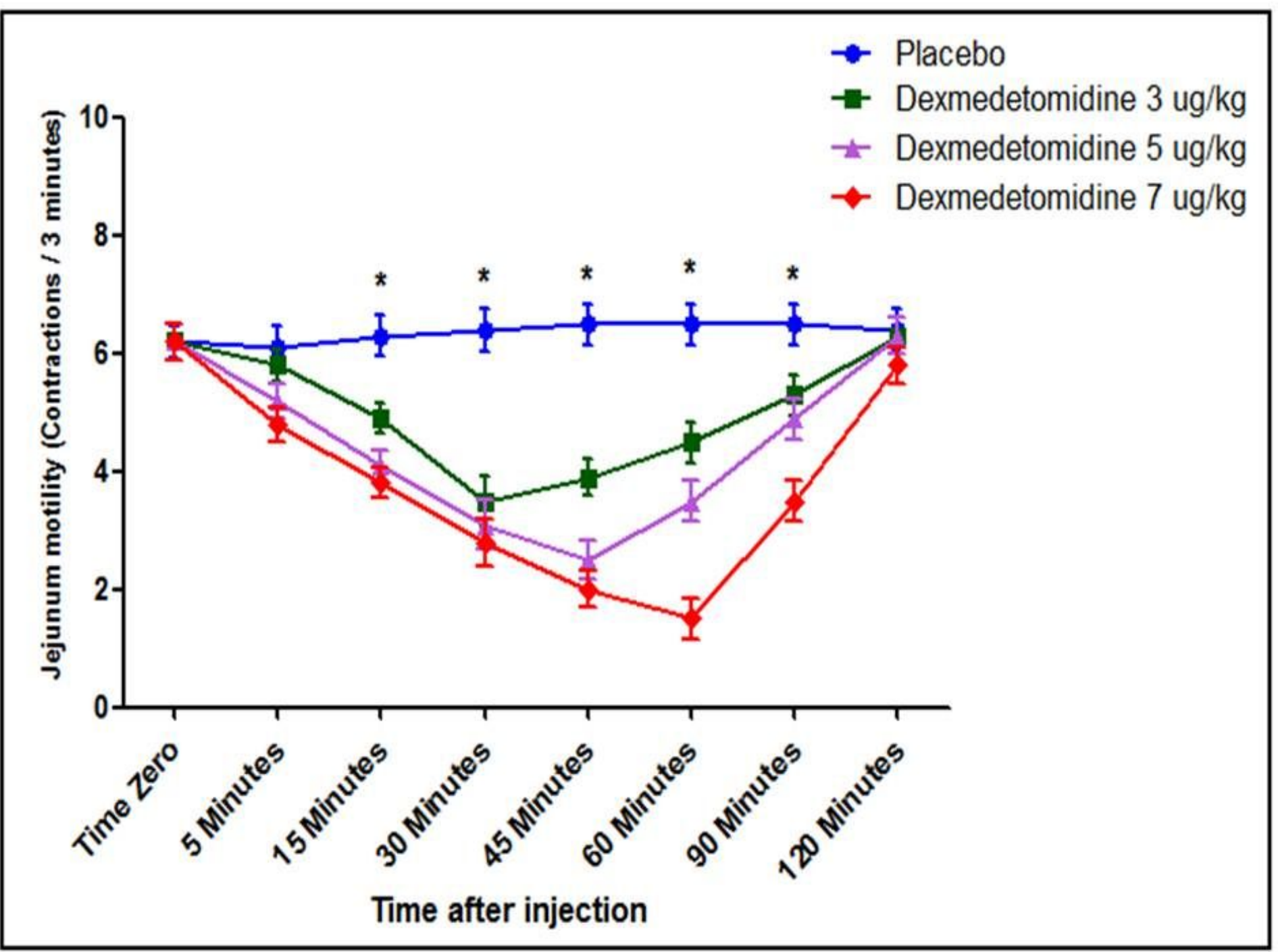

Figure 2

The jejunum motility pattern in healthy donkeys (Equus asinus) after IV administration of isotonic saline or dexmedetomidine at 3,5 , and $7 \mu \mathrm{g} / \mathrm{kg}$. Each point represents the number of contractions (contractions / 3 minutes) expressed as mean \pm standard deviation (SD) at different time points zero, 5, 15, 30, 45-, 60-, 90-, and 120-minutes post-administration. *: Mean \pm SD with a superscript asterisk at the same time point are significantly different at $\mathrm{p}<0.05$. 


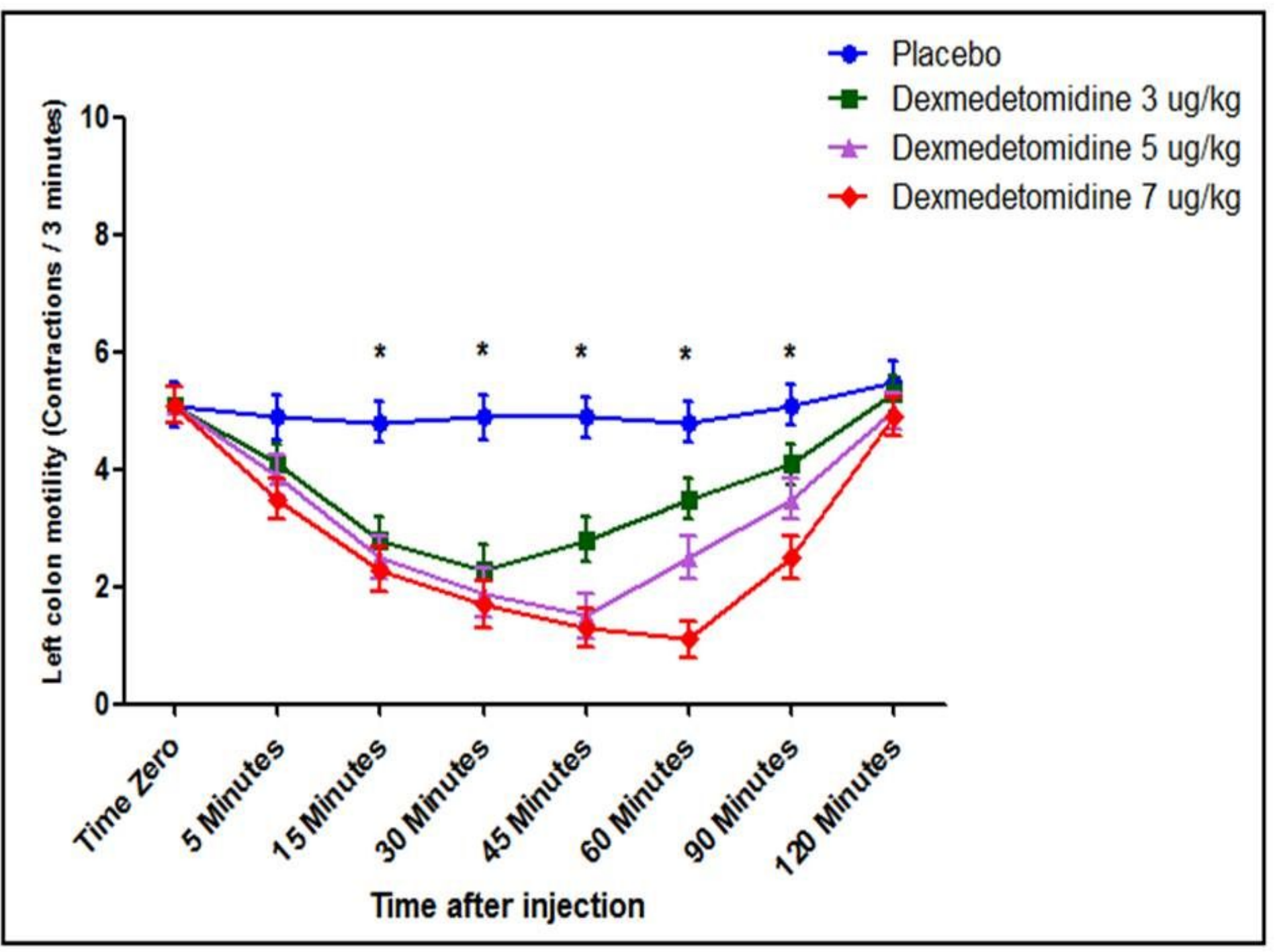

Figure 3

The left colon motility pattern in healthy donkeys (Equus asinus) after IV administration of isotonic saline or dexmedetomidine at 3, 5, and $7 \mu \mathrm{g} / \mathrm{kg}$. Each point represents the number of contractions (contractions / 3 minutes) expressed as mean \pm standard deviation (SD) at different time points zero, 5, 15, 30, 45-, 60-, 90-, and 120-minutes post-administration. *: Mean \pm SD with a superscript asterisk at the same time point are significantly different at $\mathrm{p}<0.05$. 


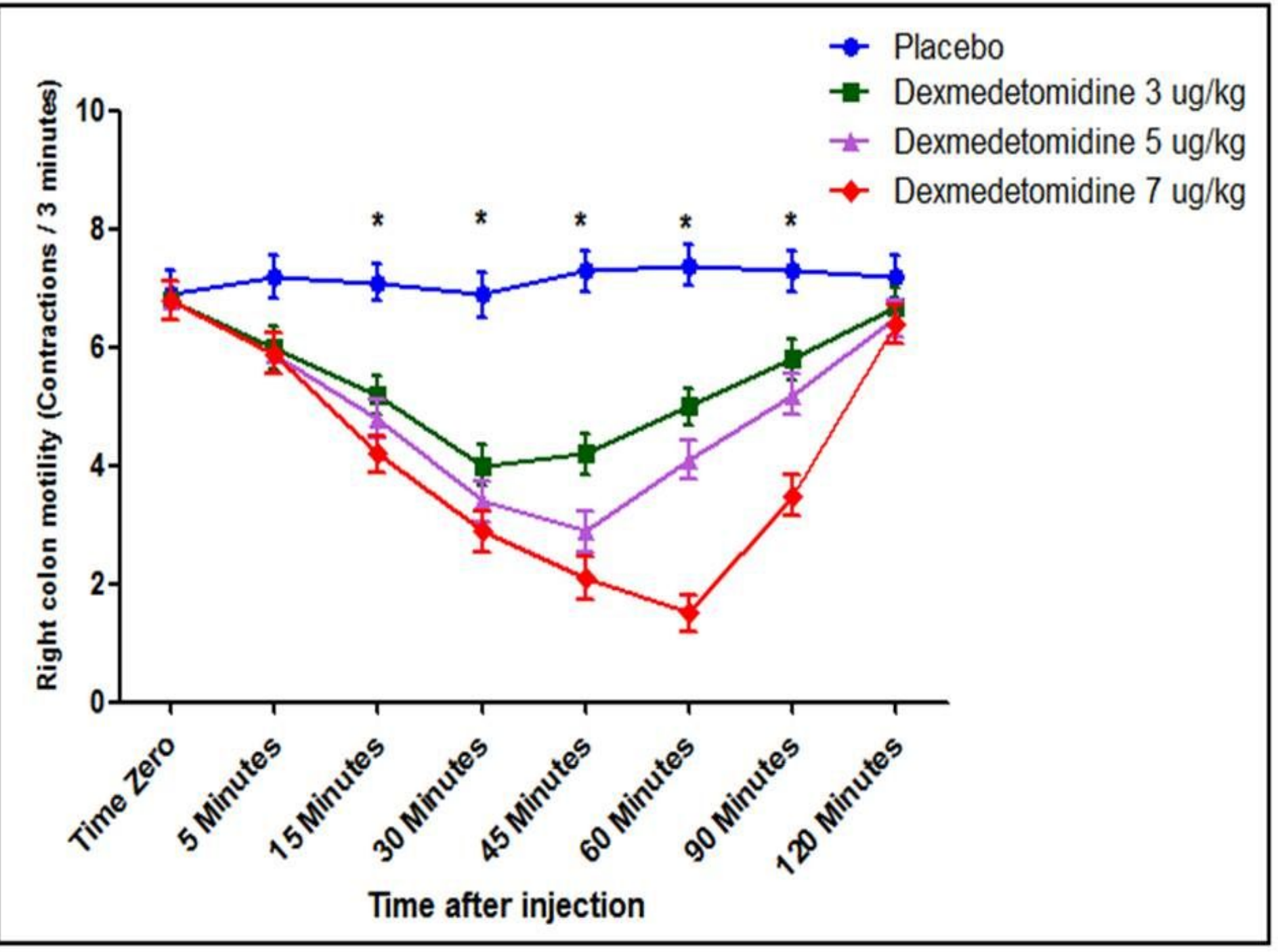

Figure 4

The right colon motility pattern in healthy donkeys (Equus asinus) after IV administration of isotonic saline or dexmedetomidine at 3,5 , and $7 \mu \mathrm{g} / \mathrm{kg}$. Each point represents the number of contractions (contractions / 3 minutes) expressed as mean \pm standard deviation (SD) at t different time points zero, 5, 15, 30, 45-, 60-, 90-, and 120-minutes post-administration. *: Mean \pm SD with a superscript asterisk at the same time point are significantly different at $p<0.05$. 


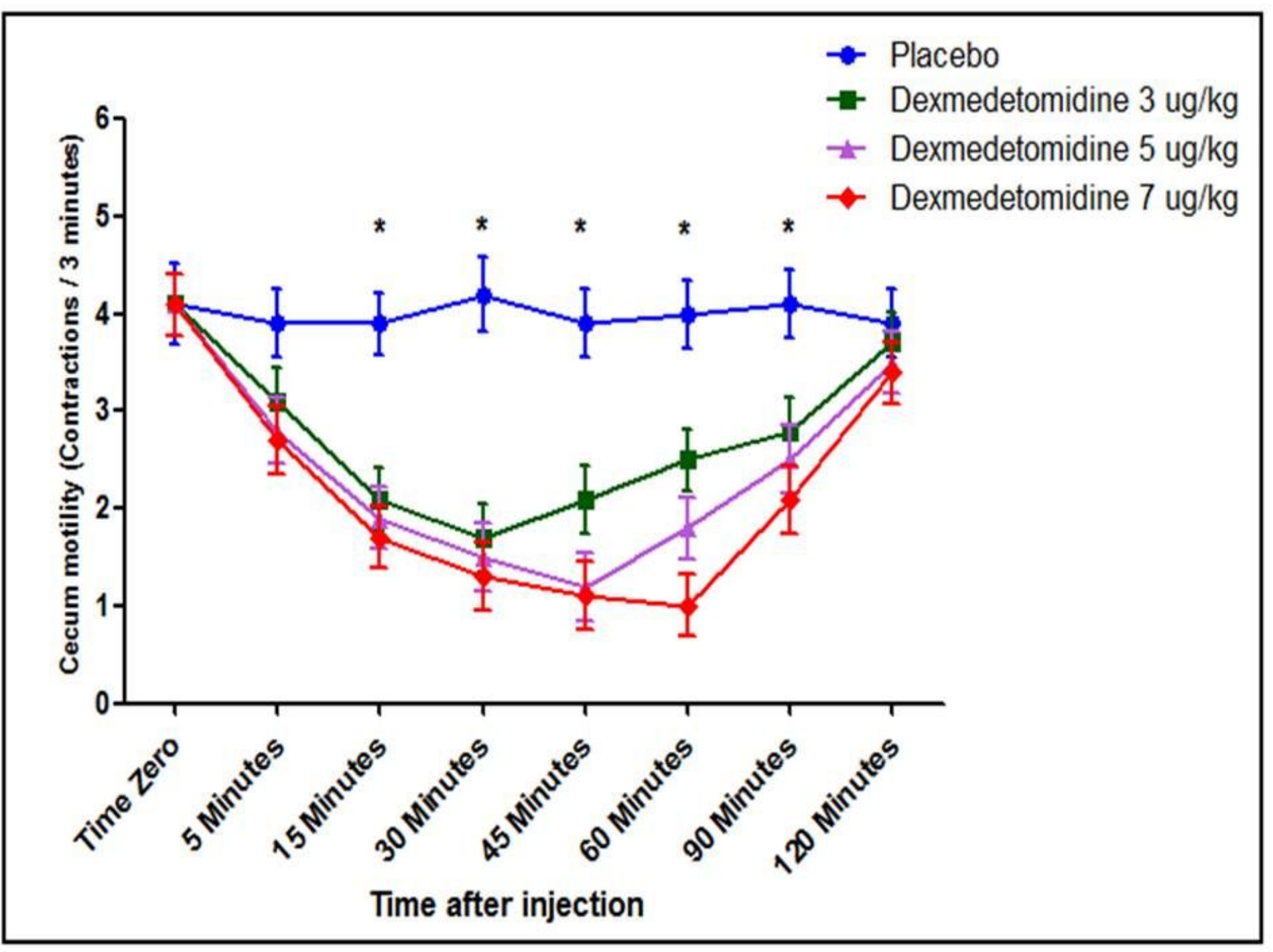

Figure 5

The cecum motility pattern in healthy donkeys (Equus asinus) IV administration of isotonic saline or dexmedetomidine at 3,5 , and $7 \mu \mathrm{g} / \mathrm{kg}$. Each point represents the number of contractions (contractions / 3 minutes) expressed as mean \pm standard deviation (SD) at t different time points zero, 5, 15, 30, 45-, 60-, 90-, and 120 -minutes post-administration. *: Mean \pm SD with a superscript asterisk at the same time point are significantly different at $p<0.05$. 